\title{
RECURSOS SÃO FUNDAMENTAIS PARA GARANTIR O DIREITO DAS PESSOAS COM DEFICIÊNCIA
}

Coluna publicada em 12.1.2016: <https://www.conjur.com.br/2016-jan-12/ contas-vista-recursos-sao-fundamentais-direito-pessoas-deficiencia $>$

Em 3 de janeiro de 2016 entrou em vigor a Lei 13.146, que instituiu o "Estatuto da Pessoa com Deficiência", ${ }^{1}$ e trouxe importantes inovaçōes voltadas a assegurar os direitos dessas pessoas que merecem especial atenção, e no mais das vezes ficam esquecidas, só delas se lembrando aqueles de alguma forma são afetados por alguma restrição, ainda que temporariamente.

Se no dia a dia enfrentamos dificuldades de diversas naturezas para as mais simples tarefas, como se vestir, alimentar, transportar, trabalhar e etc., basta uma lesão, fraturando uma perna ou um braço, para vermos estas dificuldades se tornarem um transtorno por vezes até intransponível. E pessoas com deficiências permanentes enfrentam-nas cotidianamente, exigindo uma superação que poucos enxergam e valorizam.

Nada mais justo que o Estado dê atenção a essa situação, e atue para mitigar todos esses obstáculos, proporcionando a todos mais conforto e igualdade de oportunidades, e permitindo que possam se integrar perfeitamente à vida social e serem tão ou mais produtivos que os demais em seu trabalho. Decorrência natural do princípio da igualdade, como proteção da cidadania e da dignidade da pessoa humana, eliminando as desigualdades sociais das pessoas com deficiência, uma discriminação permitida ante a necessidade de desigualar em busca dessa igualdade. ${ }^{2}$

1 Também denominada "Lei da Inclusão", publicada em 6 de julho de 2015, com 180 dias de vacatio legis.

2 Nesse sentido, JUNQUEIRA, Denise. A responsabilidade do Poder Judiciário frente à política de inserção do deficiente no mercado de trabalho: o direito constitucional como pano de fundo para a implementação dos direitos sociais. Revista de Direito Brasileira - RDB, ano 4, vol. 7, jan.-abr. 2014, p. 105. 
Isto exige, no mais das vezes, a implementação de políticas públicas que, para se tornarem efetivas, dependem de recursos, tornando o aspecto financeiro, como ocorre na maior parte das vezes, um dos mais - senão o mais - importante, e que costuma ser negligenciado, comprometendo os direitos que a nova lei pretende assegurar. E justifica chamar a atenção para este aspecto, que é o que se pretende fazer neste espaço.

Como muitas outras, as políticas públicas voltadas a assegurar o efetivo exercício dos direitos às pessoas com deficiência, e que dependem de ações governamentais que importam em gastos públicos, são bastante complexas, e requerem uma elaboração e execução bem estruturada e coordenada pelo poder público, a fim de que produzam bons resultados sem desperdício de recursos.

A Constituição estabelece ser "competência comum da União, dos Estados, do Distrito Federal e dos Municípios cuidar da saúde e assistência pública, da proteção e garantia das pessoas portadoras de deficiência" (art. 23, II), tornando todos os entes federados responsáveis, devendo fazer valer nosso federalismo cooperativo, com açōes conjuntas e coordenadas voltadas a atingir os objetivos que são comuns.

Às pessoas com deficiência deve-se assegurar o "direito à inclusão social”, cujo conteúdo compreende uma gama de outros direitos, entre os quais o direito à saúde, ao trabalho, ao transporte, à vida familiar, à educação, à acessibilidade e à igualdade. ${ }^{3}$ Vários dos quais, como se pode à primeira vista constatar, dependem de prestaçōes positivas do Estado para que se concretizem.

Observando o Estatuto já mencionado, vê-se haver capítulos destinados a cada um dos aspectos em que se desdobram os vários direitos da pessoa com deficiência, a saber: vida (capítulo 1, arts. 10 a 13), habilitação e reabilitação (arts. 14 a 17), saúde (arts. 18 a 26), educação (arts. 27 a 30), moradia (arts. 31 a 33), trabalho (arts. 34 a 38), assistência social (arts. 39 e 40), previdência social (art. 41), cultura, esporte, turismo e lazer (arts. 42 a 45) e transporte e mobilidade (arts. 46 a 52).

Fica claro que os direitos das pessoas com deficiência abrangem várias áreas de atuação do setor público, desde a assistência e previdência social, que lhes asseguram benefícios financeiros, passando por educação, saúde, segurança, transporte e tantos outros, sem esquecer da infraestrutura, que deve sempre se adaptar para atender suas condições particulares.

3 Nesse sentido, ARAUJO, Luiz Alberto David. A proteção constitucional das pessoas com deficiência. 4. ed. Brasília: Ministério da Justiça, 2011. p. 49 e seguintes. 
O Plano Nacional dos Direitos da Pessoa com Deficiência - Plano Viver Sem Limite, instituído pelo Decreto federal 7612, de 2011, já à época evidenciava com clareza que esses direitos serão assegurados com a colaboração de todos os entes federados (arts. $1^{\circ}$, parágrafo único, 9o, 10 e 11), abrangendo várias áreas e órgãos governamentais (arts. $4^{\circ}, 6^{\circ}$ e 12 ).

O que permite constatar não serem poucos os recursos indispensáveis para que os direitos sejam efetivamente implantados, e que precisam de uma gestão cooperativa e compartilhada entre entes federados, órgãos e instituições, públicas e privadas.

No âmbito da assistência social, destaca-se a garantia de um salário mínimo, benefício de prestação continuada previsto no art. 20 da LOAS. ${ }^{4} \mathrm{O}$ novo estatuto prevê também o auxílio-inclusão, destinado às pessoas com deficiência moderada ou grave (Estatuto da Pessoa com Deficiência - EPD, art. 94).

É amplo o leque no que tange ao direito à saúde, sendo-lhes assegurada atenção integral pelo SUS, extensivo às instituições privadas que dele participem de forma complementar ou recebam recursos públicos (EPD, art. 18). O Estatuto da Criança e Adolescente - ECA (Lei 8.069, de 1990), em seu art. 11, $\$ \$ 1^{\circ}$ e $2^{\circ}$, também é expresso ao garantir atendimento especializado pelo SUS à criança e adolescente portador de deficiência, incumbindo ao poder público fornecer-lhes gratuitamente medicamentos, próteses e outros recursos que forem necessários ao tratamento, habilitação ou reabilitação.

No aspecto educacional, além dos direitos que contemplam todos os cidadãos, incumbe ao poder público implementar sistema educacional inclusivo, garantindo-lhes condições de acessibilidade, atendimento educacional especializado 5 e oferta de educação bilíngue, tendo Libras (Língua Brasileira de Sinais) como primeira língua (EPD, arts. 27 e 28).

A Constituição é expressa ao consagrar vários desses direitos, consoante dispõe o art. $227, \$ 1^{\circ}$, II, ao estabelecer que o Estado deve promover "a criação de programas de prevenção e atendimento especializado para as pessoas portadoras de deficiência física, sensorial ou mental, bem como de integração social do adolescente e do jovem portador de deficiência, mediante o treinamento para o trabalho e a convivência, e a facilitação do acesso aos bens e serviços coletivos, com a eliminação de obstáculos arquitetônicos e de todas as formas de discriminação”.

4 Lei Orgânica da Assistência Social - Lei 8.742/1993.

5 Como determina o art. 208, III, da Constituição. 
A infraestrutura merece especial atenção, especialmente pela necessidade de que atenda à acessibilidade e mobilidade das pessoas com deficiência, e não foi esquecida pela Constituição, que no art. $227, \$ 2^{\circ}$, previu lei para dispor sobre normas de construção e adaptação de logradouros e dos edifícios de uso público e de fabricação de veículos de transporte coletivo, a fim de garantir acesso adequado às pessoas portadoras de deficiência (arts. 227, $\$ 2^{\circ}$, e 244 ).

As diretrizes para o desenvolvimento urbano, incluindo habitação, saneamento básico, transporte e mobilidade urbana, devem contemplar regras de acessibilidade aos locais de uso público, por meio de programas em regime de cooperação federativa [Lei 10.257, de 2001 (Estatuto da Cidade), art. 3º, III e IV, com redação dada pelo EPD, art. 113], estando várias delas expressas e detalhadas na Lei 10.098, de 2000, que estabelece as normas gerais e critérios para a promoção de acessibilidade às pessoas portadoras de deficiência ou com mobilidade reduzida.

Instrumentos financeiros como os benefícios fiscais são também de grande utilidade, como as isenções de vários tributos para os portadores de deficiência, destacando-se os que incidem sobre os veículos a eles destinados.

Nota-se que as políticas públicas voltadas à proteção das pessoas com deficiência mostram-se bem mais complexas do que pode parecer à primeira vista, especialmente por envolver todos os entes da Federação e, mais do que isso, vários setores da administração pública, o que exige uma cooperação não somente no âmbito federativo, mas também e principalmente de setores diversos do poder público, sem contar com a necessária colaboração entre os poderes, pois, como se pode constatar, as medidas que importam em ações efetivas voltadas à proteção das pessoas com deficiência são das mais variadas naturezas, envolvendo áreas tradicionalmente existentes nas diversas administrações públicas, como saúde, educação, infraestrutura etc.

A alocação de recursos para as políticas públicas voltadas às pessoas com deficiência reflete essa complexidade que atinge não somente o atendimento desta demanda, mas também muitas outras, sendo relevante mostrar as dificuldades encontradas para que se destinem recursos públicos para fazer valer os direitos, que, como se vê, têm custos.

Os direitos de pessoas com deficiência foram contemplados no Plano Plurianual (PPA) 2012-2015 da administração pública federal, programa 2063, tendo sido destinado valor ínfimo, menos de 80 mil reais para o período de quatro anos, verdadeiramente simbólico ( $\mathrm{R} \$ 79.011)$. O valor aumentou significativamente no projeto de PPA 2016-2019, que prevê o montante de R\$1.514.434 para o mesmo programa, que foi mantido (2063 - Promoção e Defesa dos Direitos das Pessoas 
com Deficiência), e desdobra-se em dois objetivos (0442 - promover a efetivação dos direitos das pessoas com deficiência e sua igualdade de oportunidades, por meio do fomento a sua autonomia, independência e segurança; e 0736 - promover a acessibilidade e a equiparação de oportunidades para pessoas com deficiência em todas as áreas da vida em sociedade), cada um com as respectivas metas, iniciativas e órgãos responsáveis.

Vê-se, pela identificação dos vários órgãos responsáveis, a necessidade de cooperação entre os diversos setores da administração, como já ressaltado. Embora as principais ações governamentais tenham como órgão responsável a Secretaria de Direitos Humanos, ${ }^{6}$ também encontramos o Ministério da Educação, o Ministério do Trabalho e Emprego, o Ministério da Cultura, o Ministério das Cidades e o Ministério do Turismo. E isso apenas neste programa, que é diretamente ligado a atender os direitos das pessoas com deficiência, mas não o único, já que muitos desses direitos são, ainda que indiretamente, atendidos em outros programas. Os benefícios assistenciais para pessoas com deficiência, por exemplo, são contemplados em dotações do Ministério do Desenvolvimento Social e Combate à Fome; os benefícios previdenciários, no Ministério da Previdência Social; e assim muitos outros.

Alguns entes da Federação criam órgãos próprios para atender os direitos das pessoas com deficiência, como é o caso do Estado de São Paulo, que tem a Secretaria de Estado dos Direitos das Pessoas com Deficiência, cuja dotação prevista para 2016 é da ordem de 70 milhões de reais. ${ }^{7}$ Mesmo assim, não é o único órgão no Estado que cuida do assunto, que tem natureza claramente intersetorial. É o caso, por exemplo, da Delegacia de Polícia das Pessoas com Deficiência, que integra a Secretaria de Segurança Pública, havendo, portanto, recursos alocados em outros órgãos. Há ainda programas orçamentários em outras unidades, como a ação "Esporte e lazer para pessoas com deficiência", da Secretaria de Esporte, Lazer e Juventude, ${ }^{8}$ a ação "Apoio à pessoa com deficiência", da Secretaria do Emprego e Relações do Trabalho, ${ }^{9}$ além de outras. No Município de São Paulo, há a Secretaria

6 Que é diretamente vinculado à Presidência da República. E, integrando a Secretaria de Direitos Humanos, está a Secretaria Nacional de Promoção dos Direitos das Pessoas com Deficiência, que cuida das políticas públicas específicas do setor.

7 Órgão 47000, Orçamento para 2016, Lei estadual 16.083, de 28.12.2015, dotação de R\$ 67.682.512,00.

8 Secretaria de Esporte, Lazer e Juventude (Órgão 41000), Programa São Paulo Mais Esporte e Lazer (4109), ação Esporte e lazer para pessoas com deficiência (27.812.4109.5117).

9 Secretaria do Emprego e Relações do Trabalho (Órgão 23000), Programa Oportunidades para inserção no mercado de trabalho (2309), ação Apoio à Pessoa com Deficiência (11.331.2309.6108). 
Municipal da Pessoa com Deficiência e Mobilidade Reduzida. Outros entes da Federação também contemplam órgãos específicos, como o Município do Rio de Janeiro (Secretaria Municipal da Pessoa com Deficiência - SMPD).

É interessante notar como o poder público vem tratando essa questão sob o ponto de vista administrativo e financeiro, o que permite analisar se está sendo adequado para atender às políticas públicas para esta finalidade, e eventualmente aperfeiçoar-se.

Leis não faltam para tornar claros os direitos das pessoas com deficiência, e o novo Estatuto vem em boa hora para sistematizá-los e reforçá-los, e não deixar dúvidas quanto à importância e necessidade de que sejam respeitados e - o que é fundamental - efetivamente implantados pelo poder público.

O importante é ficar atento. Sem recursos, dificilmente boa parte dos direitos das pessoas com deficiência se tornará realidade. A lei foi publicada, entrou em vigor, e sua aplicação precisa ser eficiente. 